\title{
Bacterial strain Pseudomonas avellanae 6CH2 with anti- Fusarium activity in mitigation of herbicidal stress in wheat plants
}

\author{
Sergey Chetverikov* , Danil Sharipov, Margarita Bakaeva, Daria Chetverikova, \\ Maksim Timergalin and Timur Rameev
}

Ufa Institute of biology - Subdivision of the Ufa Federal Research Centre of the Russian Academy of Sciences, Ufa, 450054, Russia

Received: September 26, 2020; Revised: December 2, 2020; Accepted: January 15, 2021

\begin{abstract}
The aim of this work was to study a new strain of microorganisms resistant to herbicides of different chemical structure and its impact on herbicidal stress in wheat (Triticum aestivum L.). Herbicides with synthetic auxins 2,4-D (2-ethylhexyl ether), dicamba (Octapon, Chistalan) and metsulfuron-methyl (Nanomet) had a phytotoxic (stress) effect on wheat plants, decreasing their weight up to $11 \%$, reducing the amount of chlorophylls up to $10 \%$ and increasing the proline quantity by 2.5-5.7 times in leaves. The Pseudomonas avellanae strain 6CH2 was isolated from chemical factory soil and had a number of useful properties: suppression of phytopathogenic Fusarium, herbicide-resistance, synthesis auxins and molecular nitrogen fixation. Its special features did not disappear under the influence of herbicides. Because of these properties, $P$. avellanae strain 6CH2 had an anti-stress effect on wheat plants if they were jointly treated with herbicides and bacteria. Spraying with herbicides increased the concentration of proline in wheat leaves by 1.7-2.8 times, while bacterial addition made it at least the same as in the control group. Inoculation with bacteria $P$. avellanae strain $6 \mathrm{CH} 2$ increased the total chlorophyll amount by 1.19-1.26 times against the background of herbicidal stress. Thus, bacteria P. avellanae strain 6CH2 can be used as an anti-stress agent when spraying wheat crops with herbicides.
\end{abstract}

Keywords: Pseudomonas, Wheat, Anti-fungal activity, Anti-stress effect, Chlorophyll, Proline.

\section{Introduction}

When cultivating agricultural crops, traditionally, great attention is paid to combating weed flora. Along with soil tillage and crop rotations, chemical herbicides are the main methods for controlling unwanted vegetation. They are used more often than other plant protection products (Aktar et al., 2009). Such widespread and intensive use provokes the spread of resistant weeds, which in turn prompts agricultural producers to increase the doses of herbicides and combine several active substances in order to improve the efficacy of chemical herbicides (Zargar et al., 2019). The efforts to control perennial and persistent weeds can also inhibit crop plants (Light et al., 2005; Kumar and Singh, 2010) and results in residual effects next year (Su et al., 2018). The current situation will remain until the next generation of products aiming with a different mechanism of action compared to currently produced herbicides.

Therefore, the search for means to reduce herbicidal stress in agricultural crops becomes relevant. The use of specialized strains of microorganisms for this purpose began to be considered only recently and is reflected in a few publications. Bourahla et al. (2018) ascertained the ability of the Pseudomonas putida strain to improve physiological and biochemical parameters (chlorophyll, carotenoids, malondialdehyde, enzyme activity) and reduce the manifestations of oxidative stress in durum wheat seedlings against the background of $10^{-4} \mathrm{M}$ norfluazone in hydroponic culture. Burkholderia cepacia strain mitigated toxicity, increased the size, dry matter, the ability to form nodules, the content of nutrients in seeds of chickpea plants, reduced the levels of proline and malondialdehyde if the amount of glyphosate in the soil was $4.332 \mathrm{mg} / \mathrm{kg}$ (Shahid and Khan, 2018). Strain Mesorhizobium in the presence of cladinophope (up to 1.2 $\mathrm{mg} / \mathrm{kg}$ of soil) increased biomass, nodule and leghemoglobin content, nutrient uptake, seed yield and grain protein in chickpeas (Ahemad and Khan, 2010b). Quizalafop-p-ethyl- and clodinafop-tolerant Rhizobium isolate increased biomass, symbiotic properties, nutrients uptake and seed yield of lentil (Ahemad and Khan, 2010a) and pendimethalin resistant cereals growth stimulating Azotobacter salinestris (Chennappa et al., 2018) were also described.

The described bacteria, which can increase plant resistance to herbicidal stress, belong to different genera: Pseudomonas, Rhizobium, Mesorhizobium, Bacillus, Azotobacter. All of them are rhizosphere or endophytic microorganisms that can actively interact with the plant. The authors of the research note that they have such properties as nitrogen-fixing and phosphatemobilizing activity, synthesis of auxins, exopolysaccharides, 1aminocyclopropane-1-carboxylate deaminase, and siderophores.

It is believed that bacteria associated with plants can enhance the non-specific stress resistance (including

\footnotetext{
* Corresponding author e-mail: chelab007@yandex.ru.
} 
resistance to herbicides), inducing universal protective reactions in the plants (Tétard-Jones and Edwards, 2015). Therefore, it is possible to obtain a single strain of microorganisms that favorably affects plants against a wide range of different herbicides. The publications we found do not contain data on whether a single bacterium can increase the plant's resistance to herbicides of different structures or to a combination of two herbicides. Therefore, experimental testing of this possibility is actual.

The aim of our work was to study a new strain of microorganisms resistant to herbicides of different chemical structure and its impact on herbicidal stress in wheat.

Wheat was chosen because of its importance in human nutrition and a lot of publications about toxic reactivity of wheat plants to herbicides (Song et al., 2007, Bezuglova et al., 2019).

The presence of other useful qualities (fixing molecular nitrogen, fighting diseases) would increase the practical and commercial value of these bacteria.

\section{Materials and methods}

\subsection{Microorganism}

The organism of interest in this research was the bacterial strain $6 \mathrm{CH} 2$, isolated of the soil contaminated with petrochemicals from the territory of an industrial enterprise (Republic of Bashkortostan, Russia). The pure culture was characterized according to its cultural, morphological, physiological, and biochemical characteristics using the well-established procedures (Gerhardt et al., 1981; Garrity et al., 2005).

\subsection{Molecular identification of bacteria}

Isolation of total DNA was carried out according to the method described in (Wilson et al., 1995). Amplification of the 16S rRNA gene fragment was carried out using bacterial primers 27F (5`AGAGTTTGATC (A / C) TGGCTCAG 3`) and 1492R (5` ACGG (C / T) TACCTTGTTACGACTT 3') on a My Cycler amplifier (Bio-Rad Laboratories, USA). Isolation and purification of PCR products was carried out from low-melting agarose using the Wizard PCR Preps reagent kit (Promega, United States) according to the manufacturer's recommendations. Sequencing of the obtained PCR fragments of the $16 \mathrm{~S}$ rRNA gene was performed using the Big Dye Terminator v. 3.1 kit (Applied Biosystems Inc., USA) on an ABI PRIZM 3730 automated sequencer (Applied Biosystems Inc., USA) according to the manufacturer's instructions supplied.

The search for homologous sequences was carried out using the EzBioCloud databases (http://www.ezbiocloud.net/eztaxon). A dendrogram of phylogenetic similarity was constructed in the MEGA version 7 program (http://www.megasoftware.net) by the Neighbor-Joining method (Saitou and Nei, 1987) using the Kimura model (Kimura, 1980).

\subsection{Antagonism against phytopathogens}

Antagonistic potential against phytopathogens was determined during joint cultivation of bacteria and filamentous fungi in Petri dishes (Chetverikov and Loginov, 2009) on Czapek Dox agar medium. Test objects were Bipolaris sorokiniana (Sacc.) Shoemaker VKM F-
529, Fusarium culmorum (W.G. Smith) Sacc. VKM F844, F. gibbosum Appel et Wollenw VKM F-848, F. graminearum Schwabe VKM F-1668, F. solani (Mart) Sacc. VKM F-142, F. oxysporum Schltdl VKM F-137, F. nivale (Fr.) Ces. Ex Sacc. VKM F-3106, F. semitectum VKM F - 1938, F. avenaceum VKM F - 132, Alternaria alternate (Fr.) Keissl. VKM F-3047, Rhizoctonia solani J.G. Kuehn VKM F-895. Cultures were obtained from the All-Russian Collection of Microorganisms. The fungi were maintained on Czapek Dox agar.

\subsection{Measurement of bacterial nitrogenase activity}

The acetylene reduction assay was used as an indicator of nitrogenase activity of strain $6 \mathrm{CH} 2$, with ethylene used as a label and measured by gas chromatography (Hardy et al., 1973; Korshunova et al., 2013).

\subsection{Measurement of bacterial indolyl-3-acetic acid}

The capacity of strain 6CH2 to synthesize indolyl-3acetic acid (IAA) was measured by immunoenzyme assay was carried out as described (Bakaeva et al., 2020).

\subsection{Modeling herbicide stress}

For modeling herbicide stress in plants, selective herbicides containing auxin-like substances 2,4-D (2ethylhexyl ether) - Octapon, 2,4-D (2-ethylhexyl ether) and dicamba (sodium salt) - Chistalan (LLC AHK-AGRO, Russia) and metsulfuron-methyl - Nanomet (LLC Pesticides.ru, Russia) were used. They are designed to destroy perennial, annual dicotyledonous weeds that grow among spring barley, spring and winter wheat (State catalog..., 2020).

\subsection{Wheat cultivation and treatments}

Plants of soft spring wheat (Triticum aestivum L.) cultivar Kinelskaya Yubileinaya were grown in Climate Chamber MLR-352H-PE (PHC Europe BV, Netherlands) in one-liter containers filled with a mixture of sand and black soil in a ratio of 1 : 9 , at a PAR photon flux density of $190 \mu \mathrm{mol} \cdot \mathrm{m}^{-2} \cdot \mathrm{s}^{-1}$, 14 -hour photoperiod and temperature $26^{\circ} \mathrm{C}$. Soil humidity was maintained at $60-$ $80 \%$ of the total humidity capacity. On the seventh day after germination, when the third sheet start forming, plants were sprayed with a herbicide, a suspension of bacteria Pseudomonas avellanae strain 6CH2, or their mixture: per vessel $0.9 \mu$ l Octapon, $0.9 \mu$ l Chistalan, $13 \mu \mathrm{g}$ Nanomet, $5 \times 10^{7} \mathrm{CFU}$ of the strain $6 \mathrm{CH} 2$ (based on the working concentrations of herbicides taking into account the application rates according to the regulations). According to the regulations for herbicides used, the second or third leaf stage is the earliest period when herbicide treatment is acceptable. Control plants were not sprayed.

Growth and weight characteristics of shoots and roots were determined 14 days after spraying. For each variant of the experiment, 30 plants were grown.

On the third day after the treatment of plants, the content of chlorophyll and proline in the leaves was determined. The content of proline and chlorophyll in the leaves, dry weight of roots and shoots, and shoot length were determined using freshly plucked plant parts.

\subsection{Chlorophyll measurement}

The chlorophyll content was determined spectrophotometrically on spectrophotometer Selecta UV- 
2005 (Selecta, Spain) after extraction with 96\% alcohol (Vernon, 1960) and was expressed in mg / g dry weight.

\subsection{Proline measurement}

The proline content was determined using a ninhydrin reagent, as described previously (Bates et al., 1973), using a calibration curve constructed with standard L-proline («Sigma», United States) and expressed in $\mu \mathrm{g} / \mathrm{g}$ dry weight.

\subsection{Statistical analyses}

Statistical analyses were performed with descriptive statistics (mean) and two-sample unpaired t-test $(\mathrm{p}=0.05)$ to determine statistically significant differences $(\mathrm{P}<0.05)$ between treatments using MS Excel. Data were expressed as averages \pm confidence interval.

\section{Results}

The cells of the 6CH2 strain are Gram-negative nonspore-forming mobile rods with 1-4 polar flagella, grow slowly on nutrient agar. When they are cultivated on sucrose media, colonies with a diameter of 2-4 mm, round, shiny, translucent are formed. The optimum growth temperature is $23-25 \circ \mathrm{C}$. The maximum growth temperature is $35^{\circ} \mathrm{C}$. The metabolism is respiratory. Bacteria liquefied gelatin, did not reduce nitrates, formed levan, did not hydrolyze starch, did not form indole, and curdled milk poorly. They produced acid during fermentation of dextrose, sucrose, glycerin and formed a blue-green fluorescent pigment, when cultured on King B medium (King et al., 1954).

The sequence (1413 bp) of the 16S rRNA gene from the isolated strain corresponding to $21-1433$ positions of the $E$. coli nomenclature was determined and subsequently deposited in GenBank as number MT703877. The bacterial species Pseudomonas avellanae, $P$. syringae, $P$. cannabina, and $P$. mandelii were closest to the studied sample. The sequence similarity between strains $6 \mathrm{CH} 2$ and $P$. avellanae BPIC 631 was $99.15 \%$, and with $P$. syringae KCTC 12500, P. cannabina CFBP 2341, and P. mandelii NBRC 103147 - 98.94\%. To clarify the phylogenetic position of the strain, we compared its nucleotide sequence of the 16S rRNA gene and that of nearby Pseudomonas secies and constructed a dendrogram (Fig. 1).

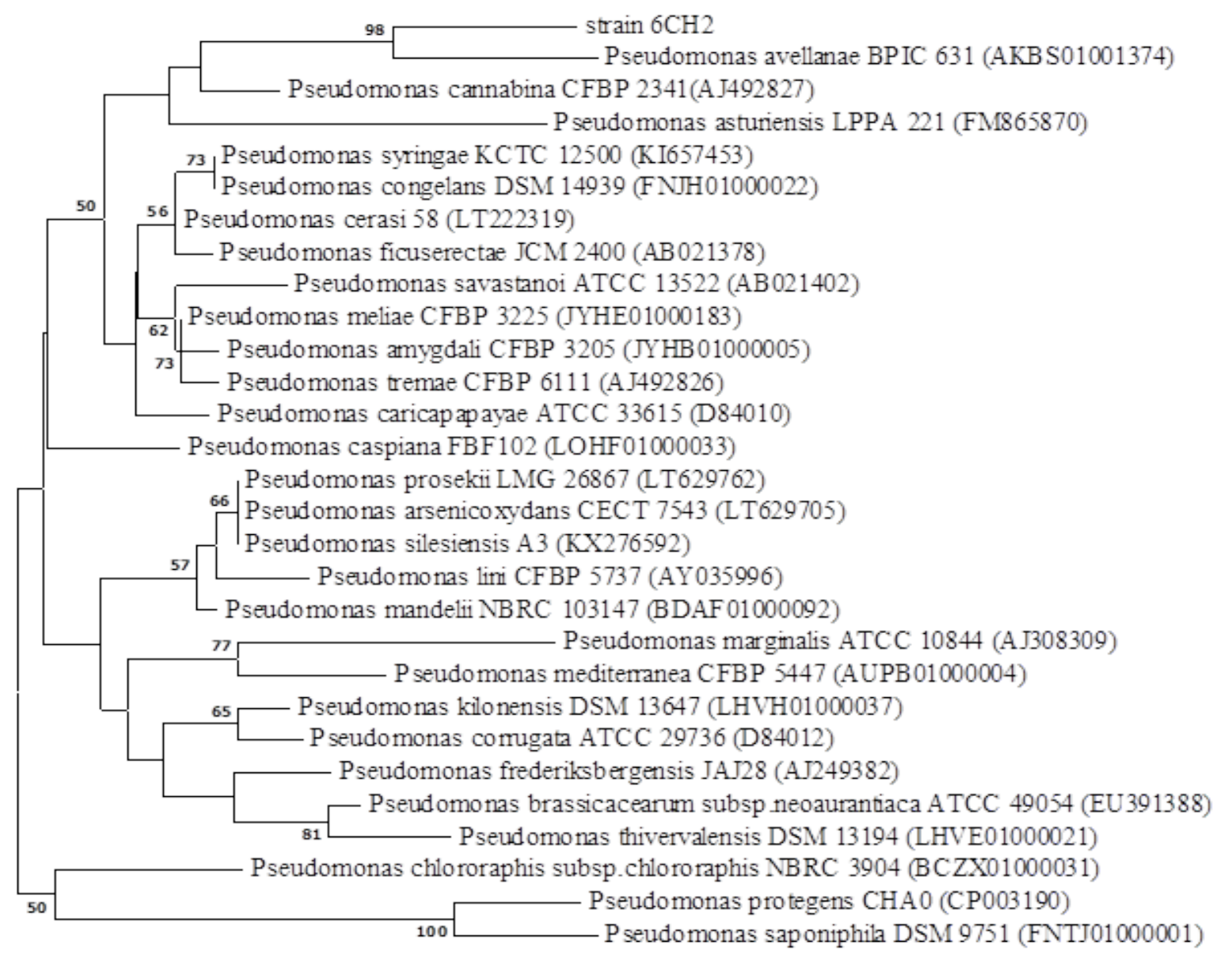

$\longmapsto$

Figure 1. Phylogenetic position of the 6CH2 strain according to the analysis of the nucleotide sequence of the 16S rRNA gene. The scale shows the evolutionary distance corresponding to 1 nucleotide change in every 1000 nucleotides. The numbers show the statistical significance of the branching order determined using the "bootstrap " analysis (the values of the "bootstrap " analysis are shown above $50 \%$ ). The data obtained was presented in this way to make it possible to identify the studied strain as Pseudomonas avellanae 6CH2. 


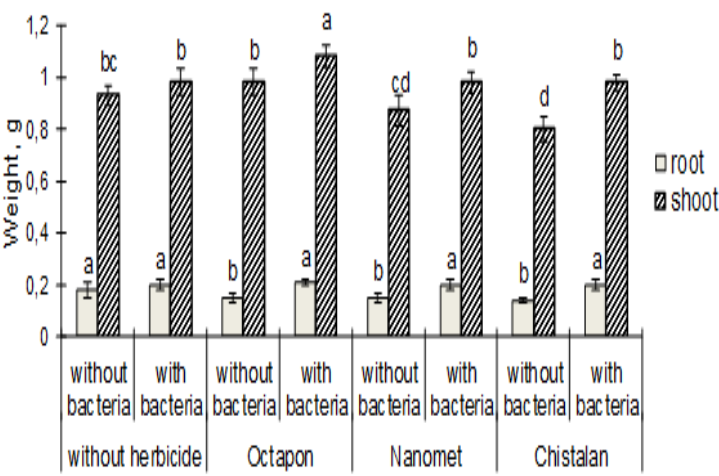

Table 1. Antagonistic activity of the bacterial strain Pseudomonas avellanae $6 \mathrm{CH} 2$

\begin{tabular}{ll}
\hline Phytopathagenic micromycetes & $\begin{array}{l}\text { Diameter of the fungal } \\
\text { growth inhibition zone, mm }\end{array}$ \\
\hline Fusarium culmorum VKM F - 844 & $12.0 \pm 1.5$ \\
F. gibbosum VKM F - 848 & $16.8 \pm 2.0$ \\
F.graminearum VKM F - 1668 & $14.6 \pm 1.4$ \\
F. nivale VKM F - 3106 & $10.4 \pm 0.5$ \\
F. semitectum VKM F - 1938 & $14.2 \pm 1.2$ \\
F. solani VKM F - 142 & $16.2 \pm 1.5$ \\
F. avenaceum VKM F - 132 & $20.6 \pm 2.2$ \\
F. oxysporum VKM F-137 & $14.4 \pm 1.3$ \\
Bipolaris sorokiniana & $\leq 5.0$ \\
Alternaria alternate VKM F-3047 & $\leq 5.0$ \\
Rhizoctonia solani VKM F-895 & $\leq 5.0$ \\
\hline
\end{tabular}

The nitrogen-fixing activity of $P$. avellanae $6 \mathrm{CH} 2$ was $19.8 \mathrm{nmol} \mathrm{C}_{2} \mathrm{H}_{4} \cdot \mathrm{h}^{-1} \cdot \mathrm{ml}^{-1}$. The nitrogenase activity did not decrease under the influence of the studied herbicides in the above-mentioned concentrations.

The herbicide-resistant strain 6CH2 was able to synthesize IAA both when grown in the presence and in the absence of the herbicides. The maximum IAA production was $189 \pm 12 \mathrm{ng} / \mathrm{ml}$ in the culture liquid without herbicides and did not decrease by more than $10 \%$ in their presence.

In our study, treatment of wheat plants with herbicides Nanomet and Chistalan at the stage of emergence of the third leaf resulted in suppression of their growth; shoot (up to $14 \%$ ) and root weight (up to $18 \%$ ) (Fig. 2), shoot length (up to $12 \%$ ) (Fig. 3) were significantly less than in the control group of plants not exposed to the herbicide. The variant with the herbicide Octapon, which slightly stimulated the mass accumulation and shoots growth, stood out from the general paradigm. This synthetic auxin, whose effect on sensitive plants is due to the excessive accumulation of auxins in them and a violation of their distribution between organs (Grossmann, 2007), worked in our case as a weak growth stimulant.

Figure 2. Effect of herbicides and spraying with strain $P$. avellanae $6 \mathrm{CH} 2$ on root and shoot weight of wheat measured 14 days after. Mean values \pm confidence interval are presented $(n=30)$. Significantly different means of each parameter are marked with different letters $(\mathrm{p} \leq 0.05)$

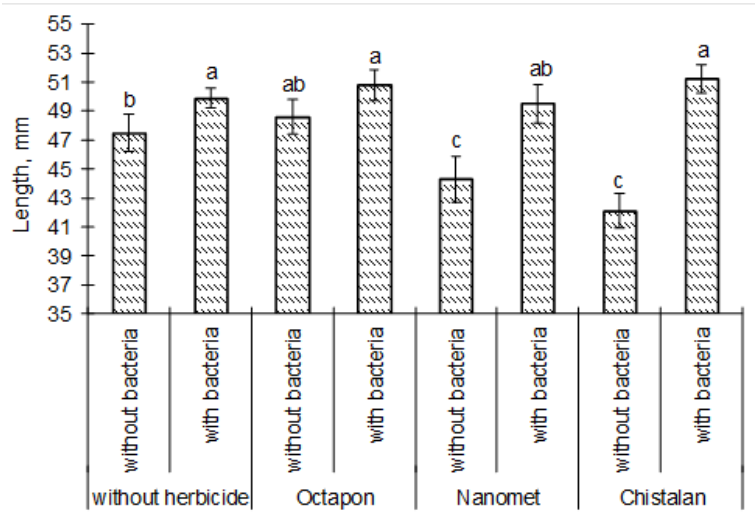

Figure 3: Effect of herbicides and spraying with strain $P$. avellanae $6 \mathrm{CH} 2$ on shoot length of wheat measured 17 days after. Mean values \pm confidence interval are presented $(n=30)$. Values sharing same letters differ non-significantly $(\mathrm{P}>0.05)$

Another manifestation of the negative effect of all tested herbicides on plants was a decrease in the total content of chlorophylls a and b (up to 10\%) (Fig. 4).

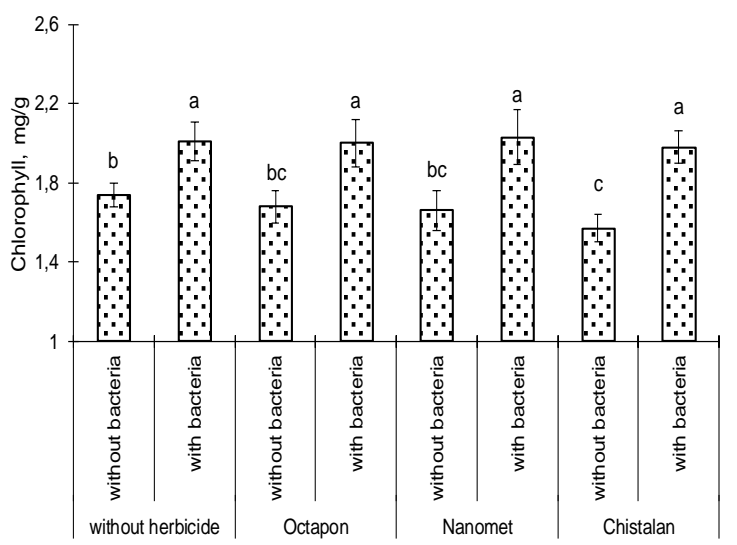

Figure 4. Effect of herbicides and spraying with strain $P$. avellanae $6 \mathrm{CH} 2$ on chlorophyll amount in wheat leafs measured 3 days after. Mean values \pm confidence interval are presented $(\mathrm{n}=30)$. Values sharing same letters differ non-significantly $(\mathrm{P}>0.05)$ 
Bacterial treatment without herbicides had a positive effect on the length of the shoots and, accordingly, on the chlorophyll amount (an increase of 16\%). Taking into account that the chlorophyll content is an important indicator of the state of plants under stress (Ashraf and Harris, 2013), it can be unambiguously asserted that bacterial treatment with the strain $6 \mathrm{CH} 2$ was not stressful for the tested plants. The positive effect of bacteria was expressed in mitigation the negative influence of the herbicide on the photosynthetic apparatus. It was reflected in the pigments quantity in plants. In all variants, inoculation with bacteria led to an increase in the total chlorophyll amount against the background of herbicidal stress.

When treating wheat plants with mixtures of bacteria and herbicides, a significant increase in all growth characteristics was observed relative to plants treated with herbicides only. The mass of plant roots reached the control parameters, and the mass and length of shoots exceeded the values in the control group by $8-16 \%$. The increase in the mass of plant can be attributed to the bacterial indolylacetic acid responsible for root system extension and improvement of absorption of mineral elements and water. Bacteria can also increase the nitrogen and phosphorus available to plants, as shown above. The assumption of improved nutrition seems plausible because the increase in plant mass occurred in all variants of the experiment with the bacterium regardless of the herbicide type.

In our experiment, spraying with herbicides increased the concentration of proline in plants (Fig. 5). If the spraying with synthetic auxins increased the concentration of proline by 3 times relative to the control, then in the case of treatment with Nanomet, the increase was more than $500 \%$. The treatment of plants with a mixture of herbicides and bacteria did not initiate the accumulation of proline; its concentration in them practically did not differ from the plants of the control group.

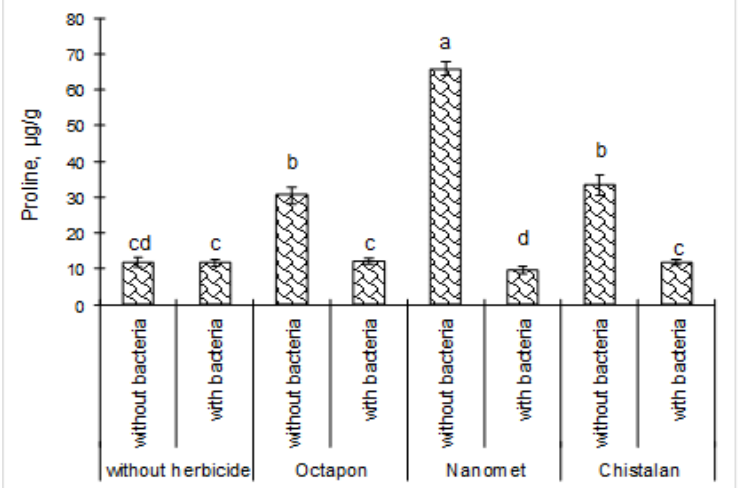

Figure 5. Effect of herbicides and spraying with strain $P$. avellanae $6 \mathrm{CH} 2$ on proline amount in wheat leafs measured 3 days after. Mean values \pm confidence interval are presented $(\mathrm{n}=30)$. Values sharing same letters differ non-significantly $(\mathrm{P}>0.05)$

\section{Discussion}

The main problem of using herbicides is their negative effect on basic agricultural crops. Herbicide treatment can cause oxidative stress in plants, which is manifested in a slowdown in growth processes and a decrease in productivity in the final (Light et al., 2005). At the same time, herbicidal treatment is the only real way to control weeds on an industrial scale, even taking into account the non-absolute selectivity of herbicides. And reducing the toxic load of herbicides on cultivated plants is a real problem.

Although it is believed that monocotyledonous plants are insensitive to the herbicides based on the synthetic auxin 2,4-D, in the case of their application before the onset of the tillering stage, inhibition of wheat plant growth was noted (Kumar and Singh, 2010). It is also believed that cereals are relatively resistant to the action of sulfonylurea herbicides, but in some cases they do not cope with their toxic effects (Barrett, 1989), not to mention the problems of dicotyledons crops that follow them in the crop rotation.

In our experiment we observed a tendency to slow growth and reduce the amount of chlorophyll in plants treated with certain herbicides. But a more obvious marker of stress was the accumulation of proline in the leaves.

The formation and accumulation of the amino acid proline is a possible physiological reaction of wheat plants to stress caused by toxic substances including herbicides (Sharma and Dietz, 2006). To date, the osmoprotective, antioxidant, signal-regulatory and other functions of this multifunctional amino acid have been established (Szabados and Savoure, 2009; de Carvalho et al., 2013).

Some authors associate the ability of cells to accumulate proline with a selective assessment of drought resistance of plant varieties and species (Chaves and Oliveira, 2004). Taking into account the fact that proline plays an important role in maintaining cellular metabolism and ensures the survival of plants in extreme conditions, we also determined its amount in wheat leaves.

Metsulfuron-methyl most strongly provoked the accumulation of proline in the leaves. We tend to associate this additional increase with the mechanism of action of sulfonylurea class herbicides on plants, the primary target of which is the acetolactate synthase (ALS) enzyme. ALS is the first enzyme on the biosynthetic pathway of branched-chain amino acids (valine, leucine and isoleucine) that functions in fungi, bacteria and higher plants (Brown and Cotterman, 1994). When it is inhibited, an excess of pyruvate and oxaloacetate are formed in plant cells, then they are transformed into $\alpha$-ketoglutarate (Fig. 6). After that, the metabolic pathway leading to the synthesis of glutamate begins to function as much as possible. It is known that in plants proline can be synthesized in two ways - from glutamate or ornithine. However, it is believed that the synthesis of proline under the influence of stress occurs mainly along the glutamate pathway (Liang et al., 2013). In some plants, more than a hundredfold increase in proline content was noted in response to unfavorable factors. 


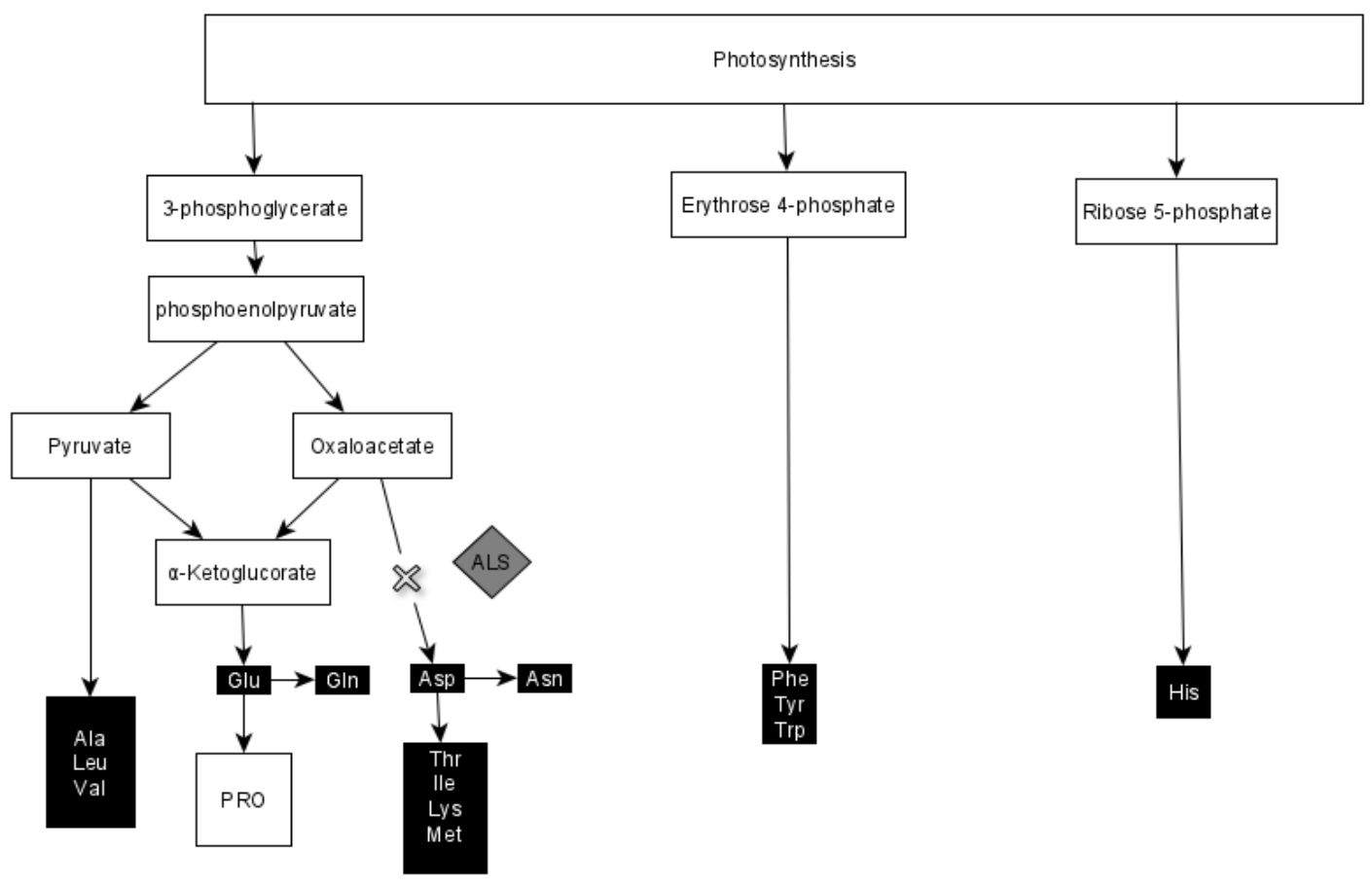

Figure 6. Biosynthesis of amino acids in plants under the influence of herbicides of the sulfonylurea class

We have previously shown that the investigated bacterial strain $P$. avellanae $6 \mathrm{CH} 2$ is stable and capable of growing at a high rate in media in the presence of herbicides based on synthetic auxins (Octapon, $10 \mathrm{ml} / \mathrm{L}$; Chistalan, $5 \mathrm{ml} / \mathrm{L}$ ) and sulfonylureas (Nanomet, $0.05 \mathrm{~g} /$ L ) (Chetverikov, 2019).

These results show that the studied bacteria exhibited other properties characteristic of PGP - bacteria: antagonism to phytopathogens, synthesis of a nitrogenase complex and phytohormones, including in the presence of herbicides. Inhibition of mycelium growth of Fusarium fungi and changes in hyphae morphology are the result of an action of metabolites of the antagonistic bacterial strain. Metabolites of Bacillus (Melentyev and Galimzyanova, 1999) and Azotobacter (Chetverikov and Loginov, 2009) had a similar impact on Fusarium. The nitrogen-fixing activity of $P$. avellanae $6 \mathrm{CH} 2$ correlated well with the values characteristic of other known nitrogen fixers (Bakaeva et al., 2020). According to the literature, the amount and activity of nitrogenase in bacteria decreases due to various stresses (Tripathi et al., 2002; Choi and Gal, 1998). Apparently, P. avellanae 6CH2 did not experience stress in the presence of herbicides and therefore the activity of nitrogenase did not decrease, while herbicides had almost no effect on nitrogen fixation and inhibition of fungal growth, their presence led to a slight decrease in the indolylacetic acid produced by bacteria. A similar decrease in IAA secretion was observed for the Burkholderia cepacia PSBB1 strain resistant to the herbicide glyphosate (Shahid and Khan, 2018).

Auxin synthesis by bacteria may be the main reason for the stimulating effect of PGPB strains on plants. Herbicide-resistant PGPB are likely to secrete auxin sufficiently even whey are applied to herbicidecontaminated soil. High production of auxins, on the contrary, can inhibit plants, as in the case of Enterobacter sp. I-3 (Park et al., 2015).
It was shown that PGPBs can change the concentration of auxins not only by their synthesis, but also by their degradation. For example, $P$. putida 1290 can use auxins as a nutrient substrate, thereby eliminating the inhibitory effect of high concentrations of exogenous auxins on the plant (Leveau and Lindow, 2005). Therefore, for achievement of a stimulating effect, the final amount of auxin must correspond to the optimum for the given species under the given environmental conditions.

Thus, will the strain 6CH2, which is tolerant to 2,4-D and sulfonylureas and capable of synthesizing IAA in their presence, mitigate herbicidal stress in plants? Will the amount of phytohormones synthesized by them be sufficient?

The treatment of plants with bacteria $6 \mathrm{CH} 2$ in addition to herbicides initiated some positive consequences: stimulation of growth, production of chlorophyll, no need to accumulate a lot of proline. Similar effects from exposure to bacteria were observed under stresses induced by herbicides paraquat (Agafonova et al., 2016), fusilad (Osman et al., 2016), and glyphosate (Shahid and Khan, 2018). In the case of herbicides of the synthetic auxins group, it should be noted that the ability to degrade 2,4-D may be one of the factors providing a favourable effect of PGPR bacteria on plants (Jacobsen, 1997, Han et al., 2015).

In the case of metsulfuron-methyl, an active substance of the herbicide Nanomet, bacteria can mitigate its negative effect on a cultivated plant, taking the impact on itself. First, detoxification can occur by accelerating the biodegradation process. Secondly, the toxicity of the herbicide can be reduced due to its primary binding to the bacterial enzyme ALS, since it has a more convenient conformation. 


\section{Conclusion}

Herbicides with synthetic auxins (Octapon, Chistalan) and sulfonylureas (Nanomet) have a phytotoxic (stress) effect on wheat plants, significantly influencing their growth, reducing the amount of chlorophylls and increasing the proline quantity. The strain $P$. avellanae $6 \mathrm{CH} 2$ isolated in this study was capable of suppressing phytopathogenic micromycetes from the genus Fusarium, resistant to the herbicides, and also exhibited properties characteristic of PGPB: the synthesis of a nitrogenase complex and phytohormones, including in the presence of herbicides. These properties allowed the $P$. avellanae strain $6 \mathrm{CH} 2$ to have an anti-stress effect (to make studied parameters at least the same as in the control group) if wheat plants were jointly treated with herbicides and bacteria.

\section{Acknowledgement}

The study was supported by funding for the theme AAAA-A19-119021390081-1 by the Ministry of Science and Higher Education of the Russian Federation

\section{Authors' contributions}

SC, DS, MB designed study, performed the statistical analysis, wrote and edited the manuscript. DC, MT, TR, DS carried out the experiments and analyzed the samples.

\section{References}

Agafonova NV, Doronina NV and Trotsenko YA. 2016. Enhanced resistance of pea plants to oxidative stress caused by paraquat during colonization by aerobic methylobacteria. Appl Biochem Microbiol., 52: 199-204.

Ahemad M and Khan MS. 2010a. Growth promotion and protection of lentil (Lens esculenta) against herbicide stress by Rhizobium species. Ann Microbiol., 60: 735-745.

Ahemad M and Khan MS. 2010b. Ameliorative effects of Mesorhizobium sp. MRC4 on chickpea yield and yield components under different doses of herbicide stress. Pestic Biochem Physiol., 98: 183-190.

Aktar W, Sengupta D and Chowdhury A. 2009. Impact of pesticides use in agriculture: their benefits and hazards. Interdiscip Toxicol., 2: 1-12.

Ashraf M and Harris PJC. 2013. Photosynthesis under stressful environments: An overview. Photosynthetica, 51: 163-190.

Bakaeva M, Kuzina E, Vysotskaya L, Kudoyarova G, Arkhipova T, Rafikova G, Chetverikov S, Korshunova T, Chetverikova D and Loginov O. 2020. Capacity of Pseudomonas strains to degrade hydrocarbons, produce auxins and maintain plant growth under normal conditions and in the presence of petroleum contaminants. Plants, 9: 379.

Barrett M. 1989. Protection of grass crops from sulfonylurea and imidazolinone toxicity. In: Hatzios KK and Hoagland RE (Eds.), Crop Safeners for Herbicides, Development, Uses, and Mechanisms of Action. London: Academic Press, Inc. pp. 195220.

Bates LS, Waldren RP and Teare IJP. 1973. Rapid determination of free proline for water-stress studies. Plant Soil, 39: 205-207.

Bezuglova OS, Gorovtsov AV, Polienko EA, Zinchenko VE, Grinko AV, Lykhman VA, Dubinina MN and Demidov A. 2019. Effect of humic preparation on winter wheat productivity and rhizosphere microbial community under herbicide-induced stress. J Soils Sediments., 19: 2665-2675.

Bourahla M, Djebbar R, Kaci Y and Abrous-Belbachir O. 2018. Alleviation of bleaching herbicide toxicity by PGPR strain isolated from wheat rhizosphere An Univ Oradea Fascicula Biol, XXV: 74-83.

Brown HM and Cotterman JC. 1994. Recent advances in sulfonylurea herbicides. In: Stetter J. (Eds.), Herbicides Inhibiting Branched-Chain Amino Acid Biosynthesis. Chemistry of Plant Protection. Berlin: Springer, Vol 10. pp. 4781.

de Carvalho K, de Campos MK, Domingues DS, Pereira LF and Vieira LGV. 2013. The accumulation of endogenous proline induces changes in gene expression of several antioxidant enzymes in leaves of transgenic Swingle citrumelo. Mol Biol Rep, 40: 3269-3279.

Chaves MM and Oliveira MM. 2004. Mechanisms underlying plant resilience to water deficits: prospects for water-saving agriculture. J Exp Bot., 55: 2365-2384.

Chennappa G, Sreenivasa MY and Nagaraja H. 2018. Azotobacter salinestris: a novel pesticide-degrading and prominent biocontrol PGPR bacteria. In: Panpatte D, Jhala Y, Shelat H and Vyas R (Eds.), Microorganisms for Green Revolution. Microorganisms for Sustainability. Singapore: Springer, Vol 7. pp. 23-43.

Chetverikov SP. 2019. Selection of anti-stress bacterial agents for the protection of agricultural plants. Estestvenny'e i texnicheskie nauki, 11: 81-84.

Chetverikov SP and Loginov ON. 2009. New metabolites of Azotobacter vinelandii exhibiting antifungal activity. Microbiology, 78: 428-432.

Choi Y-J and Gal S-W. 1998. Effects of Osmoprotectants on the Growth and Nitrogenase Activity of Rhizobium and Azospirillum under Osmotic Stress. Appl Biol Chem., 41: 53-59.

Garrity G, Brenner DJ, Krieg NR and Staley JT. 2005. Bergey's manual of systematic bacteriology, volume 2: the Proteobacteria, Part B: The Gammaproteobacteria. Springer, New York.

Gerhardt P, Murray RGE, Costilow RN, Nester EW, Wood WA, Krieg NR and Phillips GB. 1981. Manual of Methods for General Bacteriology. Amer Soc Microbiol, Washington.

Grossmann K. 2007. Auxin herbicide action: lifting the veil step by step. Plant Signal Behav., 2: 421-423.

Han L, Zhao D and Li C. 2015. Isolation and 2,4-D-degrading characteristics of Cupriavidus campinensis BJ71. Braz J Microbiol, 46: 433-441.

Hardy RWF, Burns RC and Holsten RD. 1973. Application of the acetylene-ethylene assay for measurement of nitrogen fixation. Soil Biol Biochem., 5: 47-81.

Jacobsen CS. 1997. Plant protection and rhizosphere colonization of barley by seed inoculated herbicide degrading Burkholderia (Pseudomonas) cepacia DBO1 (pRO101) in 2,4-D contaminated soil. Plant Soil, 189: 139-144.

Kimura M. 1980. A simple method for estimating evolutionary rates of base substitutions through comparative studies of nucleotide sequences. J Mol Evol., 16: 111-120.

King EO, Ward MK and Raney DE. 1954. Two simple media for the demonstration of pyocyanin and fluorescein. J Lab Clin Med., 44: 301-307.

Korshunova TU, Chetverikov SP, Mukhamatdyarova SR and Loginov ON. 2013. Oxidizing and nitrogenase activity of the bacterium Ochrobactrum sp. IB DT-5.3/2. Izvestiya samarskogo nauchnogo centra rossijskoj akademii nauk, 3-5: 1637-1640. 
Kumar S and Singh AK. 2010. A review on herbicide 2, 4-D damage reports in wheat (Triticum aestivum L.). J Chem Pharm Res., 2: 118-124.

Leveau JH and Lindow SE. 2005. Utilization of the plant hormone indole-3-acetic acid for growth by Pseudomonas putida strain 1290. Appl Environ Microbiol., 71: 2365-2371.

Liang X, Zhang L, Natarajan SK and Becker DF. 2013. Proline mechanisms of stress survival. Antioxid Redox Signal, 19: 9981011.

Light GG, Mahan JR, Roxas VP and Allen RD. 2005. Transgenic cotton (Gossypium hirsutum L.) seedlings expressing a tobacco glutathione S-transferase fail to provide improved stress tolerance. Planta, 222: 346-354.

Melentyev AI and Galimzyanova NF. 1999. Effects of metabolites of antagonistic bacilli on spore germination and development of fungi causing common root rot. Appl Biochem Microbiol., 35: 353-357.

Osman MEH, Abo-Shady AM and El-Nagar MMF. 2016 Cyanobacterial Arthrospira (Spirulina platensis) as safener against harmful effects of fusilade herbicide on faba bean plant. Re Lincei, 27: 455-462.

Park JM, Radhakrishnan R, Kang SM and Lee IJ. 2015. IAA producing Enterobacter sp. I-3 as a potent bio-herbicide candidate for weed control: a special reference with lettuce growth inhibition. Indian J Microbiol, 55: 207-212.

Saitou N and Nei M. 1987. The neighbor-joining method: a new method for reconstructing phylogenetic trees. Mol Biol Evol., 4: 406-425.

Shahid MA and Khan MS. 2018. Glyphosate induced toxicity to chickpea plants and stress alleviation by herbicide toleran phosphate solubilizing Burkholderia cepacia PSBB1 carrying multifarious plant growth promoting activities. 3 Biotech, 8(2): 131.
Sharma SS and Dietz K-J. 2006. The significance of amino acids and amino acid-derived molecules in plant responses and adaptation to heavy metal. J Exp Bot., 57: 711-726.

Song NH, Yin XL, Chen GF and Yang H. 2007. Biological responses of wheat (Triticum aestivum) plants to the herbicide chlorotoluron in soils. Chemosphere., 68: 1779-1787.

MARF. 2020. State catalog of pesticides and agrochemicals allowed for use on the territory of the Russian Federation: part 1. Pesticides. Moscow. https://mcx.gov.ru

Su WC, Sun LL, Ge YH, Wu RH, Hu HL and Lu CT. 2018. The residual effects of bensulfuron-methyl on growth and photosynthesis of soybean and peanut. Photosynthetica, 56: 670677.

Szabados L and Savouré A. 2009. Proline: a multifunctional amino acid. Trends Plant Sci, 15: 89-97.

Tétard-Jones C and Edwards R. 2016. Potential roles for microbial endophytes in herbicide tolerance in plants. Pest Manag Sci., 72: 203-209.

Tripathi A, Nagarajan T, Verma S and Le Rudulier D. 2002. Inhibition of Biosynthesis and Activity of Nitrogenase in Azospirillum brasilense Sp7 Under Salinity Stress. Curr Microbiol., 44: 363-367.

Vernon LP. 1960. Spectrophotometric determination of chlorophylls and pheophytins in plant extracts. Anal Chem., 32: 1144-1150.

Wilson K. 1995. Preparation of genomic DNA from bacteria. In: Ausube FM, Brent LR, Kingston RE, Moore DD, Seidman JG, Smith JA, and Struhl K (Eds.), Current Protocols in Molecular Biology, Green Publishing Associates, New York, pp. 241-245.

Zargar M, Bayat M, Lyashko M and Chauhan B. 2019. Postemergence herbicide applications impact canada thistle control and spring wheat yields. Agron J, 111: 2874-2880. 